\title{
Simultaneous Saccharification and Co-fermentation with a Thermotolerant Saccharomyces cerevisiae to Produce Ethanol from Sugarcane Bagasse under High Temperature Conditions
}

\author{
Wei-Lin Tu, ${ }^{\mathrm{a}, 1}$ Tien-Yang Ma, ${ }^{\mathrm{b}, 1}$ Chung-Mao Ou, ${ }^{\mathrm{a}}$ Gia-Luen Guo, ${ }^{\mathrm{a}, *}$ and Yu Chao ${ }^{\mathrm{a}}$ \\ Lignocellulosic ethanol production at high temperature offers advantages \\ such as the decrease of contamination risk and cooling cost. Recombinant \\ xylose-fermenting Saccharomyces cerevisiae has been considered a \\ promising strain for ethanol production from lignocellulose for its high \\ inhibitor tolerance and superior capability to ferment glucose and xylose \\ into ethanol. To improve the ethanolic fermentation by xylose at high \\ temperature, the strain YY5A was subjected to the ethyl methanesulfonate \\ (EMS) mutagenesis. A mutant strain T5 was selected from the EMS- \\ treated cultures to produce ethanol. However, the xylose uptake by T5 was \\ severely inhibited by the high ethanol concentration during the co- \\ fermentation in defined YPDX medium at $40{ }^{\circ} \mathrm{C}$. In this study, the \\ simultaneous saccharification and co-fermentation (SSCF) and the \\ separate hydrolysis and co-fermentation (SHCF) processes of sugarcane \\ bagasse were assessed to solve this problem. The xylose utilization by T5 \\ was remarkably improved using the SSCF process compared to the SHCF \\ process. For the SHCF and SSCF processes, $48 \%$ and $99 \%$ of the xylose \\ in the hydrolysate was consumed at $40^{\circ} \mathrm{C}$, respectively. The ethanol yield \\ was enhanced by the SSCF process. The ethanol production can reach to \\ $36.0 \mathrm{~g} / \mathrm{L}$ using this process under high-temperature conditions.
}

Keywords: Lignocellulosic ethanol; Saccharomyces cerevisiae; Inhibitor tolerance; Mutagenesis; Sugarcane bagasse; Simultaneous saccharification and co-fermentation

Contact information: a: Chemistry Division, Institute of Nuclear Energy Research, Atomic Energy Committee, Executive Yuan, No. 1000, Wunhua Road, Jiaan Village, Longtan District, Taoyuan City, 32546, Taiwan; b: Department of Biology, Functional Biology, KU Leuven, Heverlee, Belgium; 1: These two authors contributed equally to this work; *Corresponding author: glguo@iner.gov.tw

\section{INTRODUCTION}

Bioethanol is currently the dominant biofuel used in the worldwide transportation sector to replace or blend with other biofuels (Jin et al. 2019; Rajak et al. 2020). Lignocellulosic biomass, such as wood and agricultural residues, is an attractive feedstock for ethanol production due to its abundance, sustainable supply, and non-conflict with food supply. However, despite nearly a century of research to develop the cost-effective technology toward the commercial deployment of lignocellulosic ethanol, the recalcitrance of lignocellulose is still a major barrier to be economically viable via lignocellulosic ethanol production (Lynd et al. 2002; Sims et al. 2010).

The main constituents of lignocellulose are cellulose, hemicellulose, and lignin. The fractions of cellulose and hemicellulose can be used to produce biofuel by fermentation. The critical part of using lignocellulose to produce biofuel is obtaining enough fermentable monosaccharide from lignocellulose to serve as a carbon source during 
fermentation (Robak and Balcerek 2018). The separate hydrolysis and fermentation (SHF) process is commonly employed to maximize the performance of both enzymatic hydrolysis and fermentation processes for lignocellulosic ethanol production, but this increases capital and operational costs. Enzymatic hydrolysis can be performed simultaneously with fermentation in a process referred to as simultaneous saccharification and fermentation (SSF). The SSF process is considered to be favorable for lignocellulosic ethanol production due to several advantages, including removal of end-products of enzymatic hydrolysis that inhibit cellulases, higher ethanol productivity, and higher yield than that of the SHF process (Erdei et al. 2012; Jin et al. 2012). The main problem in the SSF process is the different optimum temperatures for enzymatic hydrolysis and fermentation. The optimal temperature for cellulases $\left(50^{\circ} \mathrm{C}\right)$ is remarkably higher than the fermenting temperature suitable for Saccharomyces cerevisiae $\left(30{ }^{\circ} \mathrm{C}\right)$, the most used organism for industrial ethanol production. The SSF process has been currently exerted at lower temperatures to coordinate with the growth temperature of fermenting strains, which slows enzymatic hydrolysis efficiency and results in reduced fermentation rates and yields (Eklund et al. 1990; Sassner et al. 2006). To improve the SSF process for efficient conversion of lignocellulose into ethanol, using thermotolerant organisms to compromise the optimal temperature for yeast fermentation and enzymatic hydrolysis has been considered a promising solution (Banat et al. 1992; Fonseca et al. 2008; Yanase et al. 2010). In addition, high-temperature fermentation offers several advantages, such as reduction of contamination risk and cooling cost, especially in tropical countries (Chamnipa et al. 2018).

Besides glucose, xylose is the most abundant sugar in lignocellulosic biomass. Thus, an ideal organism for lignocellulosic ethanol production with both superior glucose and xylose co-fermentation capacity and high-temperature tolerance is required. Some studies have identified genetically engineered thermotolerant yeasts Kluyveromyces marxianus and Hansenula polymorpha capable of converting xylose to ethanol at elevated temperatures $\left(42\right.$ to $45{ }^{\circ} \mathrm{C}$ ), whereas the low ethanol productivity and slow xylose utilization are still the major problems that need to be overcome (Dmytruk et al. 2008; Zhang et al. 2015). To date, $S$. cerevisiae is still considered a favorable microorganism for industrial ethanol production because of its high ethanol productivity and high inhibitor tolerance (Cunha et al. 2019; Favaro et al. 2019). Numerous efforts have engineered $S$. cerevisiae to ferment xylose by introducing homologous or heterologous xylose metabolic pathways, resulting in promising xylose fermentation properties (Kuyper et al. 2005; HahnHägerdal et al. 2007; Watanabe et al. 2007). The S. cerevisiae strains with increased thermotolerance have been obtained by genetic engineering or evolutionary engineering strategies. For example, the evolved S. cerevisiae strain ISO12 developed by long-term adaptation strategy can grow and ferment the non-detoxified spruce hydrolysate at $39{ }^{\circ} \mathrm{C}$ (Wallace-Salinas and Gorwa-Grauslund 2013). In another study, the engineered $S$. cerevisiae strain Z-06 could enhance cell stress tolerance and glycolysis flux at high temperature by overexpression of the TSL1 gene (Ge et al. 2013). In addition, other researchers have identified other genes, such as TPS1, RSP5, HSP100, SSK2, PPG1, and $P A M 1$, that are important for the thermotolerance of S. cerevisiae (An et al. 2011; Kim et al. 2011; Shahsavarani et al. 2012). There have been a considerable number of studies for improving fermentation of glucose at elevated temperature by $S$. cerevisiae (Benjaphokee et al. 2012; Lu et al. 2012). However, the number of studies for alcoholic fermentation of xylose at elevated temperatures is still limited (Ismail et al. 2013; Jin et al. 2013). 
The inhibition of xylose consumption by recombinant xylose-fermenting $S$. cerevisiae in glucose and xylose co-fermentation at elevated temperature was observed in a previous study (Jin et al. 2013). However, there is a need for more detailed information about the inhibitory factors affecting xylose fermentation by recombinant $S$. cerevisiae at elevated temperatures. The effects of glucose and ethanol on xylose fermentation by xylose-fermenting $S$. cerevisiae at elevated temperature have not been reported. In this study, the effects of glucose and ethanol on xylose utilization in a synthetic medium by a recombinant xylose-utilizing $S$. cerevisiae strain YY5A were tested. In addition, improving the thermotolerance of YY5A by ethyl methanesulfonate (EMS) mutagenesis was demonstrated in this work. In contrast, to assess a better process for xylose conversion in non-detoxified lignocellulosic hydrolysate from sugarcane bagasse at high-temperature, SSCF and SHCF processes were tested and discussed in this study.

\section{EXPERIMENTAL}

\section{Strain and Medium}

The genetically engineered strain YY5A used in this study has been described elsewhere (Ma et al. 2012). The strain was maintained on a yeast extract peptone dextrose (YPD) agar plate (10 g/L yeast extract, $20 \mathrm{~g} / \mathrm{L}$ peptone, $20 \mathrm{~g} / \mathrm{L}$ D-glucose, and $20 \mathrm{~g} / \mathrm{L}$ agar) at $30{ }^{\circ} \mathrm{C}$. The mutagenized cells by EMS (Sigma-Aldrich, St. Louis, MO, USA) treatment were selected on the yeast extract peptone xylose (YPX) agar plate $(10 \mathrm{~g} / \mathrm{L}$ yeast extract, $20 \mathrm{~g} / \mathrm{L}$ peptone, $20 \mathrm{~g} / \mathrm{L}$ D-xylose, and $20 \mathrm{~g} / \mathrm{L}$ agar) at $40{ }^{\circ} \mathrm{C}$.

\section{Fermentation in a Synthetic Medium}

The seed cultures were aerobically grown in $50 \mathrm{~mL}$ of YPD in 250-mL Erlenmeyer flasks at $30{ }^{\circ} \mathrm{C}$ for $16 \mathrm{~h}$. For xylose fermentation, experiments were carried out at different temperatures, at which $10 \mathrm{~mL}$ of the seed culture was inoculated into $40 \mathrm{~mL}$ of YPX medium in a $250-\mathrm{mL}$ Erlenmeyer flask. The initial fermentation broth contained $10 \mathrm{~g} / \mathrm{L}$ yeast extract, $20 \mathrm{~g} / \mathrm{L}$ peptone, and 40 to $50 \mathrm{~g} / \mathrm{L}$ D-xylose. An initial dry cell weight (DCW) of approximately 0.8 to $1.2 \mathrm{~g} / \mathrm{L}$ was used. The fermentation processes were performed in triplicate at 30,37 , or $40{ }^{\circ} \mathrm{C}$ with agitation at $150 \mathrm{rpm}$. For glucose and xylose cofermentation experiments at elevated temperatures in a $250-\mathrm{mL}$ Erlenmeyer flask, $10 \mathrm{~mL}$ of the seed culture was inoculated into $40 \mathrm{~mL}$ of yeast extract peptone dextrose (YPDX) medium in the presence of different initial concentrations of glucose and xylose. The initial fermentation broth contained $10 \mathrm{~g} / \mathrm{L}$ yeast extract, $20 \mathrm{~g} / \mathrm{L}$ peptone, 18 to $74 \mathrm{~g} / \mathrm{L}$ glucose, and 40 to $50 \mathrm{~g} / \mathrm{L}$ xylose. An initial DCW of approximately $1.2 \mathrm{~g} / \mathrm{L}$ was used, and all fermentation processes were performed in triplicate at 37 or $40{ }^{\circ} \mathrm{C}$ with agitation at 150 rpm. For xylose fermentation with varying concentrations of initial ethanol at different temperatures in a $250-\mathrm{mL}$ Erlenmeyer flask, $10 \mathrm{~mL}$ of the seed culture was inoculated into $40 \mathrm{~mL}$ of YPX medium in the presence of varying initial concentrations of ethanol. The initial fermentation broth contained $10 \mathrm{~g} / \mathrm{L}$ yeast extract, $20 \mathrm{~g} / \mathrm{L}$ peptone, $47 \mathrm{~g} / \mathrm{L}$ xylose, and $2.5,12,23$, or $33 \mathrm{~g} / \mathrm{L}$ ethanol. An initial DCW of approximately $1.2 \mathrm{~g} / \mathrm{L}$ was used, and all fermentation processes were performed in triplicate at 30,37 , and $40{ }^{\circ} \mathrm{C}$ with agitation at $150 \mathrm{rpm}$. 


\section{Strain Mutagenesis by EMS Treatment}

Strain mutagenesis was carried out with EMS. The seed cultures were aerobically grown in $10 \mathrm{~mL}$ of YPD in 50-mL Erlenmeyer flasks at $30^{\circ} \mathrm{C}$ for $16 \mathrm{~h}$. Cells in a $500 \mu \mathrm{L}$ fresh culture were collected by centrifugation, washed twice with sterile water, and resuspended in $1 \mathrm{~mL}$ EMS solution (4\% (v/v)). The cells were incubated with EMS at 30 ${ }^{\circ} \mathrm{C}$ for 50 min to obtain a survival rate of $10 \%$. The mutagenesis was then stopped by adding $500 \mu \mathrm{L}$ freshly made sodium thiosulfate $(\%(\mathrm{w} / \mathrm{v}))$. The mutagenized cells were then collected by centrifugation, washed twice with $500 \mu \mathrm{L}$ freshly made $5 \%(\mathrm{w} / \mathrm{v})$ sodium thiosulfate, and resuspended in sterile water. Following mutagenesis, the cells were immediately plated on a YPX agar plate and incubated at $40^{\circ} \mathrm{C}$. Well-grown colonies with different xylose fermentation capacities were selected for further studies.

\section{Pretreated Sugarcane Bagasse}

The pretreated sugarcane bagasse was provided by Dr. Wen-Hua Chen of Institute of Nuclear Energy Research (INER), Taoyuan, Taiwan. Sugarcane bagasse with a moisture content of $61.3 \%$ was chopped into smaller pieces $(\leq 2 \mathrm{~cm})$ with a shredder and used as raw material. The acid-catalyzed steam explosion experiments were performed in a pilotscale continuous pretreatment system at the Institute of Nuclear Energy Research, Taiwan (Chen et al. 2013). The reaction condition of the acid-catalyzed steam explosion process was $200{ }^{\circ} \mathrm{C}$ for a residence time of $1 \mathrm{~min}$. Subsequently, the pretreated sugarcane bagasse slurry was collected and separated into solid residues and liquid portions by a separator for further study.

\section{Separate Hydrolysis and Co-fermentation}

In the SHCF process, the enzymatic hydrolysis process was performed in a $5-\mathrm{L}$ fermenter with a working volume of $3 \mathrm{~L}$ by fed-batch mode. The two-fold diluted liquid fractions were transferred to a 5 - $\mathrm{L}$ fermenter, and the $\mathrm{pH}$ was adjusted to 6.0 by adding 10 $\mathrm{M} \mathrm{NaOH}$. Subsequently, the CTec3 cellulase enzyme (Novozymes, Bagsværd, Denmark) was added at $0 \mathrm{~h}$. The enzyme activity was set at $15 \mathrm{FPU} / \mathrm{g}$ water-insoluble solids (WIS), and the enzymatic hydrolysis reaction was performed at $50{ }^{\circ} \mathrm{C}$ for $120 \mathrm{~h}$. The solid residues were added at time periods of 0,2 , and $4 \mathrm{~h}$ to a final WIS of $13 \%$. The $\mathrm{pH}$ was maintained at around 5.5 to 5.8 using $10 \mathrm{M} \mathrm{NaOH}$ with agitation at $250 \mathrm{rpm}$. After enzymatic hydrolysis, the hydrolysate slurry was adjusted to $6 \mathrm{pH}$, and the fermentation was performed in a 5-L fermenter with a working volume of $2 \mathrm{~L}$. Then, $400 \mathrm{~mL}$ of the seed culture was centrifuged and inoculated into $2 \mathrm{~L}$ of the sugarcane bagasse hydrolysate and initiated with an inoculum of $1.2 \mathrm{~g} / \mathrm{L} \mathrm{DCW}$ at $40{ }^{\circ} \mathrm{C}$ with agitation at $250 \mathrm{rpm}$.

\section{Simultaneous Saccharification and Co-fermentation}

The SSCF process was performed in a 5-L fermenter with a working volume of 2 $\mathrm{L}$ by fed-batch mode. The liquid fractions of pretreated sugarcane bagasse were transferred to a 5-L fermenter, and the $\mathrm{pH}$ was adjusted to 6.0 by adding $10 \mathrm{M} \mathrm{NaOH}$. The yeast cells and CTec3 were added to the liquid fractions at $0 \mathrm{~h}$, with an inoculum of $1.2 \mathrm{~g} / \mathrm{L} \mathrm{DCW}$. The enzyme activity was set at 15 FPU/g WIS. The enzymatic hydrolysis and cofermentation reaction was performed at $40{ }^{\circ} \mathrm{C}$ for $120 \mathrm{~h}$. The solid residues were added at time periods of 0,2 , and $4 \mathrm{~h}$ to a final WIS of $13 \%$. The $\mathrm{pH}$ was maintained around 5.5 to 5.8 using $10 \mathrm{M} \mathrm{NaOH}$ with agitation at $250 \mathrm{rpm}$. 


\section{Analysis}

Concentrations of ethanol, glucose, xylose, xylitol, glycerol, and acetic acid were determined by high performance liquid chromatography (HPLC) (Jasco, Tokyo, Japan) equipped with a refractive index detector. An HPX-87H ion-exclusion column (Bio-Rad Laboratories, Hercules, CA, USA) was used for separation. The HPLC apparatus was operated using $5 \mathrm{mM} \mathrm{H}_{2} \mathrm{SO}_{4}$ as the mobile phase with a flow rate of $0.6 \mathrm{~mL} / \mathrm{min}$. Cell growth was monitored by measuring the absorbance at $600 \mathrm{~nm}$ using a spectrophotometer U-3000 (HITACHI, Chiyoda, Tokyo, Japan). The DCW was determined in triplicate using an infrared moisture analyzer FD-720 (Kett Electric Laboratory, Otaku, Tokyo, Japan). Next, $10 \mathrm{~mL}$ of cell cultures were rinsed with sterile water, and the DCW was determined by the FD-720. The identified cellulose, hemicellulose, and lignin component contents of the pretreated sugarcane bagasse were determined according to laboratory analytical procedures from the National Renewable Energy Laboratory (Sluiter et al. 2008), Table 1. The carbohydrate content was determined by measuring the hemicellulose (xylan and arabinan) and cellulose (glucan) compositions of the derived sugars.

Table 1. Composition of the Pretreated Sugarcane Bagasse ${ }^{a}$

\begin{tabular}{|c|c|c|c|}
\hline Name & $\begin{array}{c}\text { Content in Liquid } \\
\text { Fraction (g/L) }\end{array}$ & Name & $\begin{array}{c}\text { Content in Solid } \\
\text { Fraction (\%) }\end{array}$ \\
\hline Glucose & $17.8 \pm 0.9$ & Glucan & $47.0 \pm 0.4$ \\
\hline Xylose & $57.6 \pm 0.1$ & Xylan & $2.9 \pm 0.6$ \\
\hline HMF & $0.3 \pm 0.1$ & Araban & $0.3 \pm 0.1$ \\
\hline Furfural & $2.4 \pm 0.1$ & Lignin & $26.2 \pm 1.2$ \\
\hline Acetic acid & $5.0 \pm 0.1$ & - & - \\
\hline
\end{tabular}

a: The pretreatment using acid-catalyzed steam explosion process at $200{ }^{\circ} \mathrm{C}$ for 1 min with $1 \%$ dilute sulfuric acid solution

b: Values are the averages the standard deviations of three independent experiments based on dry weight

\section{RESULTS AND DISCUSSION}

\section{Effect of Temperature on Xylose Fermentation by YY5A}

A microbial strain that can efficiently ferment glucose and xylose into ethanol and tolerate both high-temperature and multiple inhibitors is a prerequisite for efficiently converting lignocellulosic biomass into ethanol. Previous studies have successfully developed the recombinant xylose-utilizing S. cerevisiae strain YY5A (Hahn et al. 2007). However, the thermotolerance of YY5A in xylose fermentation remains unclear. To assess the effect of temperature on xylose fermentation performance of YY5A, ethanolic xylose fermentation in the YPX medium (41.5 g/L xylose as a carbon source) was conducted at 30, 37, and $40{ }^{\circ} \mathrm{C}$. The fermentation by YY5A was initiated with an inoculum of approximately $0.8 \mathrm{~g} / \mathrm{L} \mathrm{DCW}$. In the xylose fermentation, cell concentrations of YY5A were 6.8, 5.5, and 2.3 g/L DCW at 30, 37, and $40{ }^{\circ} \mathrm{C}$ after $24 \mathrm{~h}$ fermentation, respectively (Fig. 1a). The results indicate an inhibition effect on the cell growth of YY5A at $40{ }^{\circ} \mathrm{C}$. After 24 $\mathrm{h}$ of fermentation, YY5A produced $13.6 \mathrm{~g} / \mathrm{L}$ ethanol at $30^{\circ} \mathrm{C}$, with a yield of $0.37 \mathrm{~g} / \mathrm{g}_{\text {consumed }}$ xylose; $15.0 \mathrm{~g} / \mathrm{L}$ ethanol at $37{ }^{\circ} \mathrm{C}$, with a yield of $0.38 \mathrm{~g} / \mathrm{g}_{\text {consumed xylose; }}$ and $7.6 \mathrm{~g} / \mathrm{L}$ ethanol at $40{ }^{\circ} \mathrm{C}$, with a yield of $0.35 \mathrm{~g} / \mathrm{g}$ consumed xylose (Fig. 1c). 
(a)

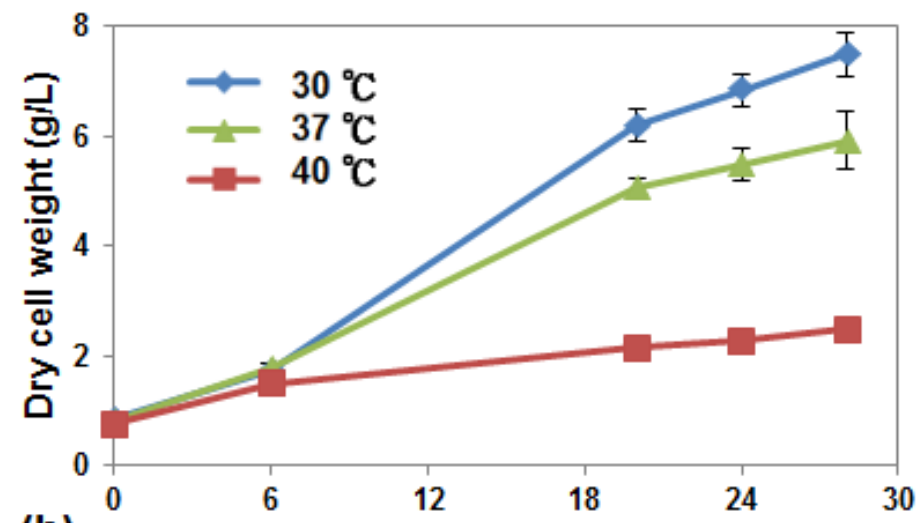

(b)

Time (h)

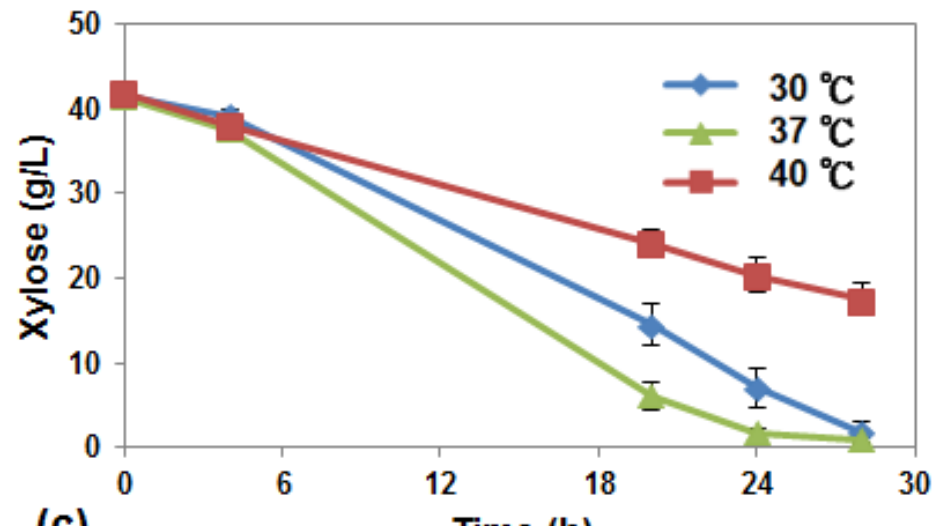

(c)

Time (h)

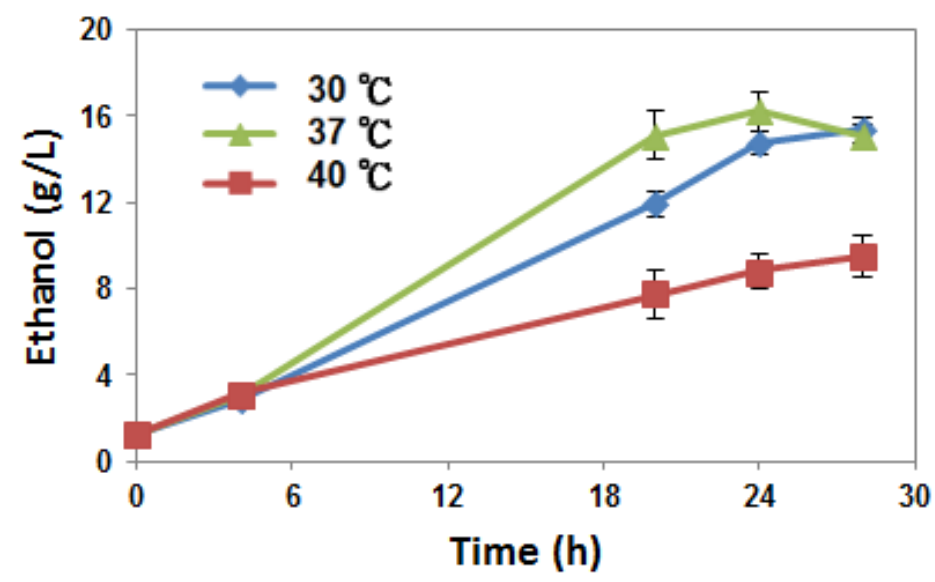

Fig. 1. The variation of (a) cell growth; (b) xylose consumption; and (c) ethanol production during xylose fermentation by the recombinant yeast strain YY5A at 30,37 , and $40^{\circ} \mathrm{C}$

The results showed a higher ethanol yield by YY5A at $30^{\circ} \mathrm{C}$ and $37^{\circ} \mathrm{C}$ than at 40 ${ }^{\circ} \mathrm{C}$. Moreover, the specific consumption rates of xylose were different from volumetric xylose consumption rates in the initial $24 \mathrm{~h}$ of fermentation. The total consumptions of xylose in the initial $24 \mathrm{~h}$ of fermentation were $36.7,39.8$, and $21.6 \mathrm{~g} / \mathrm{L}$ at 30,37 , and 40 ${ }^{\circ} \mathrm{C}$, respectively. The total increments of dry cell weight in the initial $24 \mathrm{~h}$ of fermentation were $6.1,4.7$, and $1.5 \mathrm{~g} / \mathrm{L}$ at 30,37 , and $40^{\circ} \mathrm{C}$, respectively. According to above results, the specific xylose consumption rates at 30,37 and $40{ }^{\circ} \mathrm{C}$ were $0.25,0.35$, and 0.60 
$\mathrm{g} / \mathrm{g} \cdot \mathrm{DCW} / \mathrm{h}$, and the volumetric xylose consumption rates were $1.53,1.66$, and $0.90 \mathrm{~g} / \mathrm{L} / \mathrm{h}$, respectively (Fig. 1a and 1b). The specific xylose consumption rate represents how much xylose can be consumed by $1 \mathrm{~g}$ YY5A/h and volumetric xylose consumption rate represents the consumption of xylose in the medium per hour. The specific growth rate and the volumetric xylose consumption rate for the xylose fermentation at $40{ }^{\circ} \mathrm{C}$ was lower than that at 30 and $37{ }^{\circ} \mathrm{C}$, whereas the higher specific xylose consumption rate was at $40{ }^{\circ} \mathrm{C}$ rather than that at 30 and $37^{\circ} \mathrm{C}$. The results suggested that the elevated temperature inhibits the cell growth of YY5A but stimulates the xylose assimilation efficiency by fermenting cells. Consistent with this work, it has been observed that the activities of xylose reductase from Neurospora crassa and xylitol dehydrogenase and from Scheffersomyces stipitis increased with the elevated reaction temperature during an in vitro enzyme activity assay (Zang et al. 2015). Therefore, the increase of the specific xylose consumption rates by YY5A at elevated temperatures could be explained by the elevated activity of xylose metabolizing enzymes.
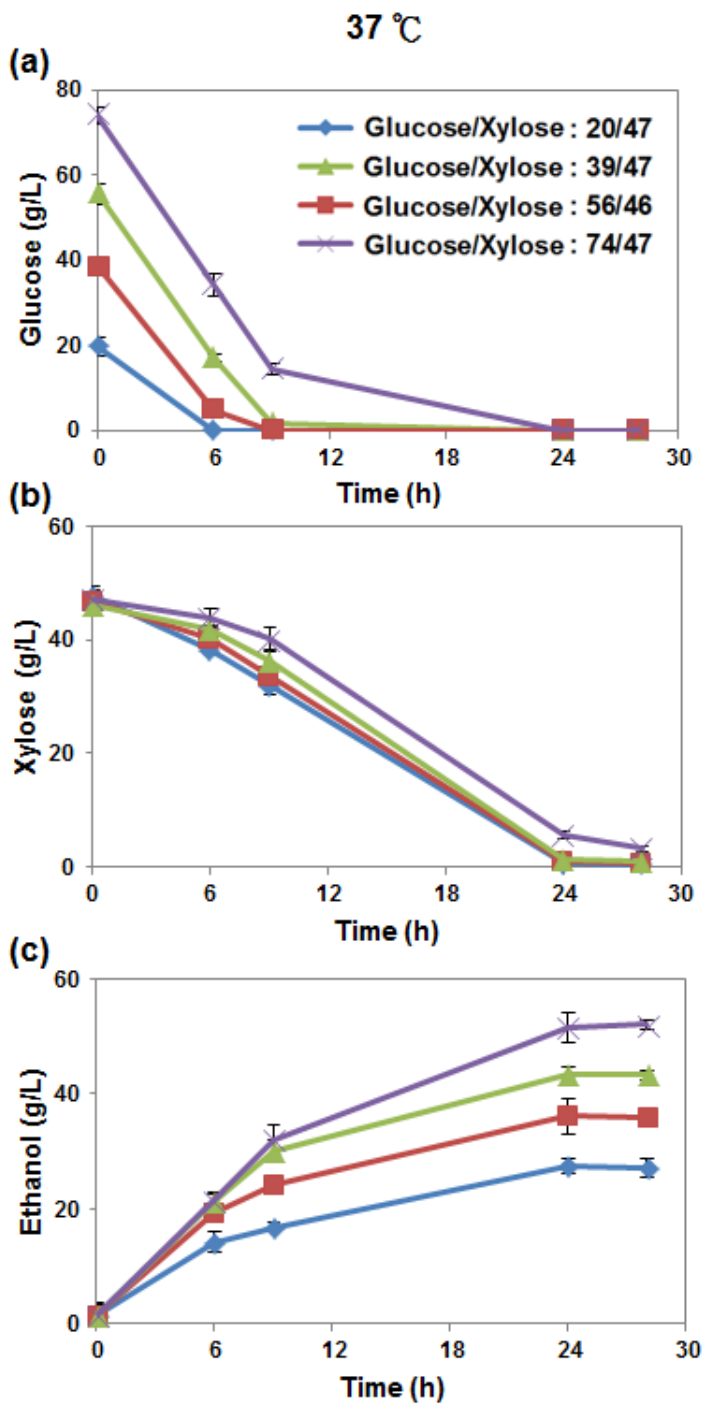
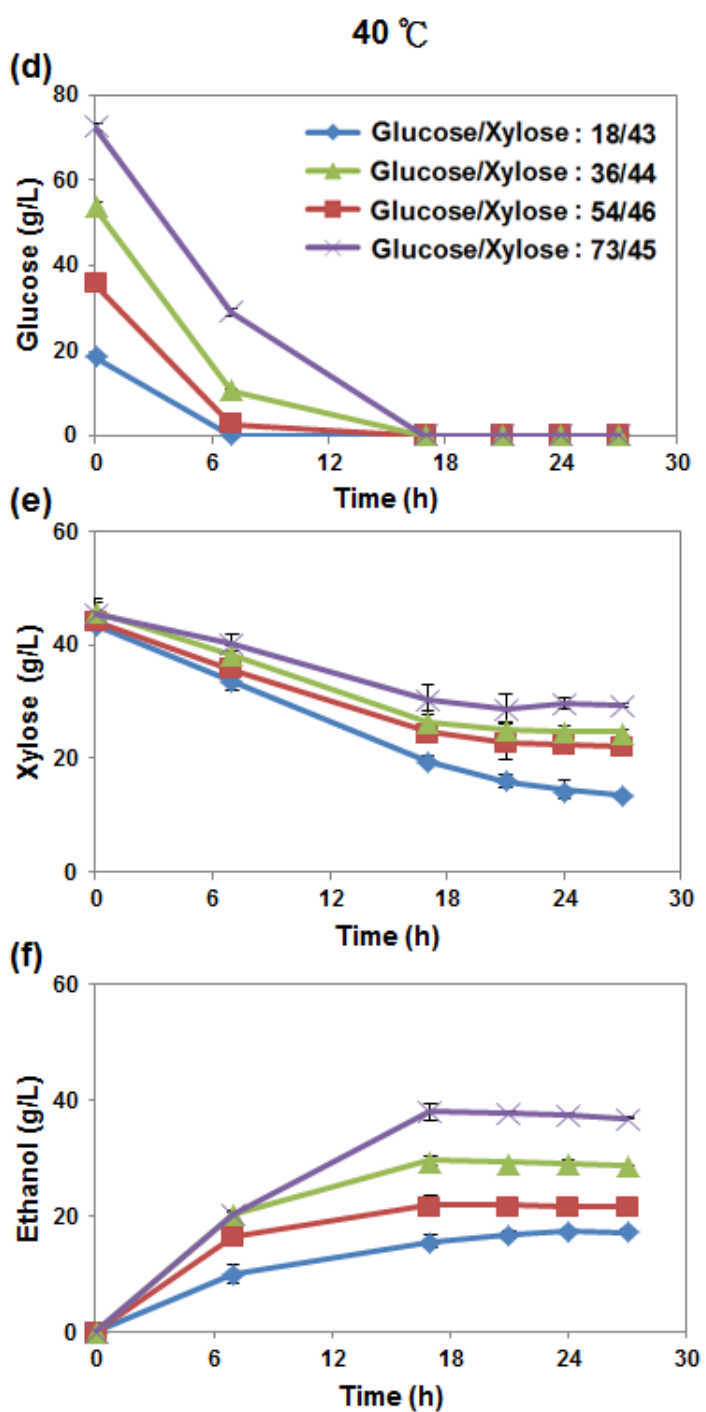

Fig. 2. Variation of ( $a$ and d) glucose consumption; ( $b$ and e) xylose consumption; and (c and f) ethanol production during co-fermentation by the recombinant yeast strain $\mathrm{YY} 5 \mathrm{~A}$ at $37^{\circ} \mathrm{C}$ or 40 ${ }^{\circ} \mathrm{C}$ 


\section{Effect of Initial Glucose Concentration on Co-fermentation of a Glucose and Xylose Mixture by YY5A at Different Temperatures}

Previous research has shown that the xylose utilization by recombinant xylosefermenting $S$. cerevisiae at a high temperature of $40{ }^{\circ} \mathrm{C}$ is inhibited in glucose and xylose co-fermentation (Jin et al. 2013). It is still unclear how well the recombinant strain YY5A could co-ferment glucose and xylose at elevated temperatures. To assess this, ethanolic cofermentation by YY5A in YPDX medium with different initial concentrations of glucose were conducted at $37{ }^{\circ} \mathrm{C}$ and $40{ }^{\circ} \mathrm{C}$ (Fig. 2). The co-fermentation by YY5A was initiated with an inoculum of approximately $1.2 \mathrm{~g} / \mathrm{L}$ DCW. After $24 \mathrm{~h}$ of co-fermentation at $37{ }^{\circ} \mathrm{C}$, the consumptions of xylose were $46.9 \mathrm{~g} / \mathrm{L}, 45.9 \mathrm{~g} / \mathrm{L}, 44.6 \mathrm{~g} / \mathrm{L}$, and $41.5 \mathrm{~g} / \mathrm{L}$ (Fig. 2b). The concentrations of ethanol were $51.5 \mathrm{~g} / \mathrm{L}, 43.3 \mathrm{~g} / \mathrm{L}, 36.1 \mathrm{~g} / \mathrm{L}$, and $27.4 \mathrm{~g} / \mathrm{L}$ (Fig. 2c) at different initial concentrations of glucose $(20,39,56$, and $74 \mathrm{~g} / \mathrm{L}$, respectively) (Fig. 2a). After $24 \mathrm{~h}$ of co-fermentation at $40{ }^{\circ} \mathrm{C}$, the consumptions of xylose were $28.9 \mathrm{~g} / \mathrm{L}, 21.8$ $\mathrm{g} / \mathrm{L}, 21.1 \mathrm{~g} / \mathrm{L}$, and $15.7 \mathrm{~g} / \mathrm{L}$ (Fig. $2 \mathrm{e}$ ), and the concentrations of ethanol were $37.4 \mathrm{~g} / \mathrm{L}, 29.1$ $\mathrm{g} / \mathrm{L}, 21.7 \mathrm{~g} / \mathrm{L}$, and $17.3 \mathrm{~g} / \mathrm{L}$ (Fig. 2f) at different initial concentrations of glucose $(18,36$, 54, and $73 \mathrm{~g} / \mathrm{L}$, respectively) (Fig. 2d). In addition, the volumetric xylose consumption rate for YY5A in the YPDX medium increased at both $37{ }^{\circ} \mathrm{C}$ (all conditions) and $40{ }^{\circ} \mathrm{C}$. This was more than the case of YPX fermentation (Fig. 1), in which xylose was the only carbon source. Similar results were observed in a previous study, in which the xylose consumption rate for the recombinant $S$. cerevisiae increased during the co-fermentation of glucose and xylose, which could be explained by the increased biomass concentration via glucose assimilation (Ma et al. 2012).

\section{Effect of Initial Ethanol Concentration on Xylose Fermentation by YY5A at Different Temperatures}

Ethanol is an inhibitory factor for yeast growth. It can affect the RNA and protein synthesis, denature cellular proteins, and disrupt the membrane integrity (Birch and Walker 2000; Ding et al. 2009). The xylose conversion by recombinant $S$. cerevisiae has been found to be inhibited by ethanol, which interferes with the cell membrane to inhibit the xylose transport (Meinander and Hahn-Hägerdal 1997). In contrast, the yeast fermentation at high temperature increases the fluidity in membranes (Suutari et al. 1990). Thus, it could be speculated that the higher ethanol concentration produced from the higher initial glucose concentration in glucose and xylose co-fermentation could aggravate the inhibition for xylose metabolism of YY5A at high temperature.

To understand the effect of ethanol on xylose fermentation at different temperatures, YY5A was used in YPX medium (47 $\mathrm{g} / \mathrm{L}$ xylose as a carbon source) to ferment xylose in the presence of the same initial concentrations of ethanol at 30,37, and $40{ }^{\circ} \mathrm{C}$. During $24 \mathrm{~h}$ of fermentation, it was observed that the decreases of biomass growth rates and xylose consumption rates for YY5A as the initial ethanol concentrations increased under all conditions of temperature (Fig. 3a, 3d, and 3g), particularly at the elevated temperatures of $37^{\circ} \mathrm{C}$ and $40^{\circ} \mathrm{C}$. A comparison of the profiles revealed the effect of ethanol on xylose fermentation by YY5A at different temperatures (Fig. 3b, 3e, and 3h). There were no remarkable differences in ethanol yield for YY5A at $30{ }^{\circ} \mathrm{C}$ under all conditions of different initial ethanol concentrations (Fig. 3c, 3f, and 3i), whereas decreases were observed in an initial ethanol concentration above $23 \mathrm{~g} / \mathrm{L}$ at $37^{\circ} \mathrm{C}$, and that above 12 $\mathrm{g} / \mathrm{L}$ at $40{ }^{\circ} \mathrm{C}$ (Fig. 3). The inhibitory effect of ethanol on xylose utilization for YY5A strictly corresponded to the varying temperature. Lower ethanol concentrations in synthetic medium were preferred for xylose fermentation by YY5A at elevated temperatures. 

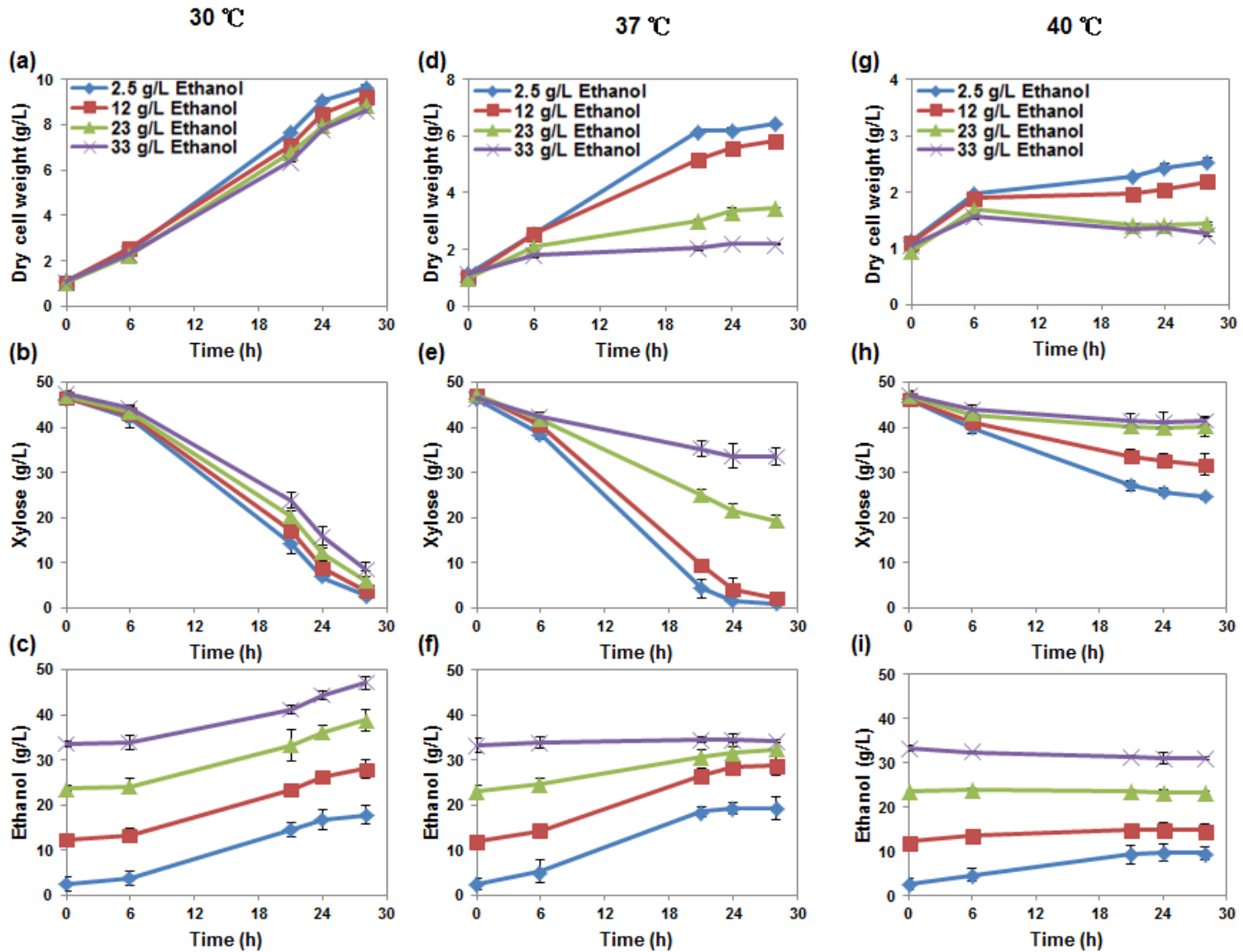

Fig. 3. Comparison of xylose fermentation by the recombinant yeast strain YY5A in the presence of varying initial ethanol concentrations at 30,37 , and $40^{\circ} \mathrm{C}$. (a) Cell growth at $30^{\circ} \mathrm{C}$; (b) xylose consumption at $30^{\circ} \mathrm{C}$; (c) ethanol production at $30^{\circ} \mathrm{C}$; (d) Cell growth at $37^{\circ} \mathrm{C}$; (e) xylose consumption at $37^{\circ} \mathrm{C}$; (f) ethanol production at $37^{\circ} \mathrm{C}$; (g) Cell growth at $40^{\circ} \mathrm{C}$; (h) xylose consumption at $40^{\circ} \mathrm{C}$; and (i) ethanol production at $40^{\circ} \mathrm{C}$

\section{Improving Xylose Fermentation of YY5A at High Temperature by EMS Mutagenesis}

To improve the xylose fermentation ability of YY5A strain at high temperature, it was subjected to mutagenesis by EMS. Sixteen well-grown colonies on YPX agar plates at $40{ }^{\circ} \mathrm{C}$ were selected from the EMS-treated cultures. After the screening of 16 mutants through a comparison of ethanol yield and xylose consumption rate in YPX medium at 40 ${ }^{\circ} \mathrm{C}$, the best mutant strain with a superior xylose fermentation capacity was selected and designated as strain T5. To further compare the fermentation capacity between T5 and YY5A at high temperature, ethanolic fermentation was evaluated in YPX medium (1\% yeast extract, $2 \%$ peptone, and $4.5 \%$ xylose) and YPDX medium (1\% yeast extract, $2 \%$ peptone, $6 \%$ glucose, and $4.5 \%$ xylose) at $40{ }^{\circ} \mathrm{C}$. The xylose consumption of YY5A and T5 was $27.8 \mathrm{~g} / \mathrm{L}$ (Fig. 4a) and $34.3 \mathrm{~g} / \mathrm{L}$ (Fig. 4c) at $24 \mathrm{~h}$, respectively. During the glucose and xylose co-fermentation, the xylose consumption of YY5A and T5 was $21 \mathrm{~g} / \mathrm{L}$ (Fig. 4b) and $19 \mathrm{~g} / \mathrm{L}$ (Fig. 4d) at $24 \mathrm{~h}$, respectively. After $16 \mathrm{~h}$ of co-fermentation, the xylose consumption rates of both strains were slowed after glucose was completely consumed, this phenomenon was consistent with the above results in co-fermentation (Fig. 2). In contrast, the slightly higher ethanol concentration was obtained by T5 (13.5 g/L) compared 
to YY5A (10.4 g/L) at $40 \mathrm{~h}$ (Fig. 4a and 4c). The results indicate that the xylose fermentation capacity of YY5A at high temperature was improved by EMS mutagenesis, especially in the fermentation of YPX medium. However, there still was inhibition of high ethanol concentration on xylose utilization by the thermotolerant T5 strain during the cofermentation at high temperature.

(a)

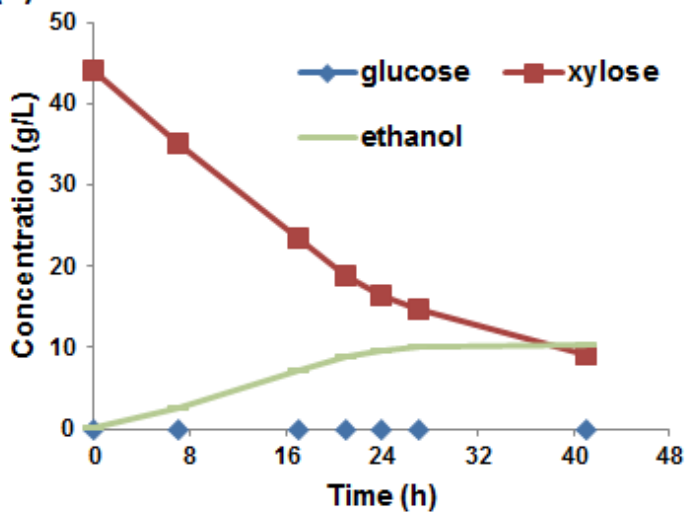

(b)

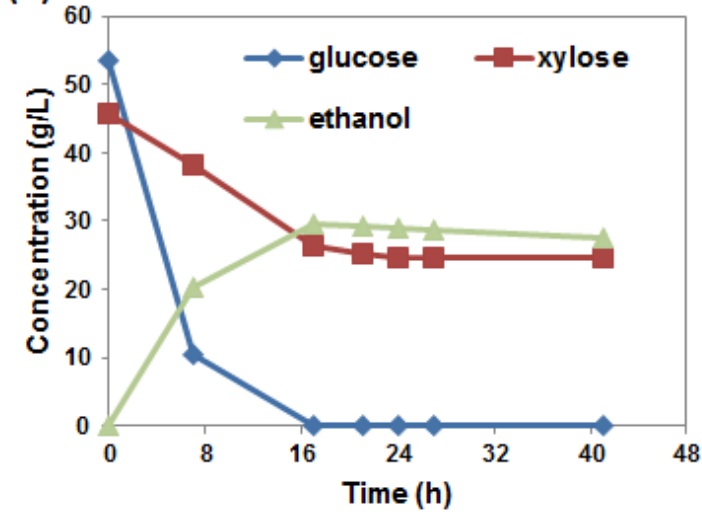

(c)

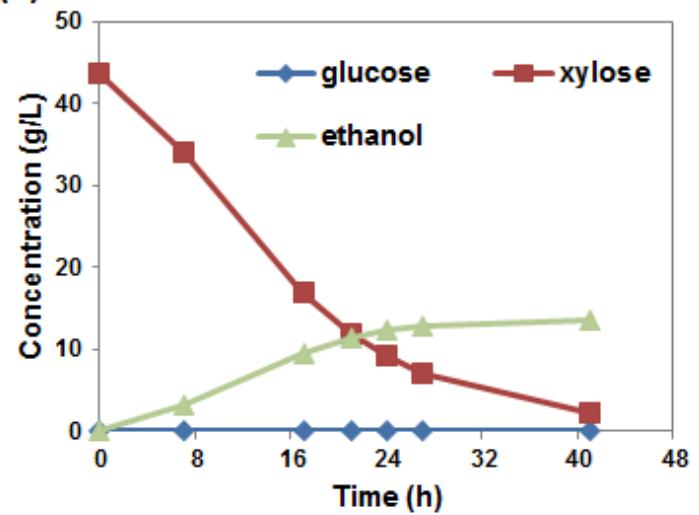

(d)

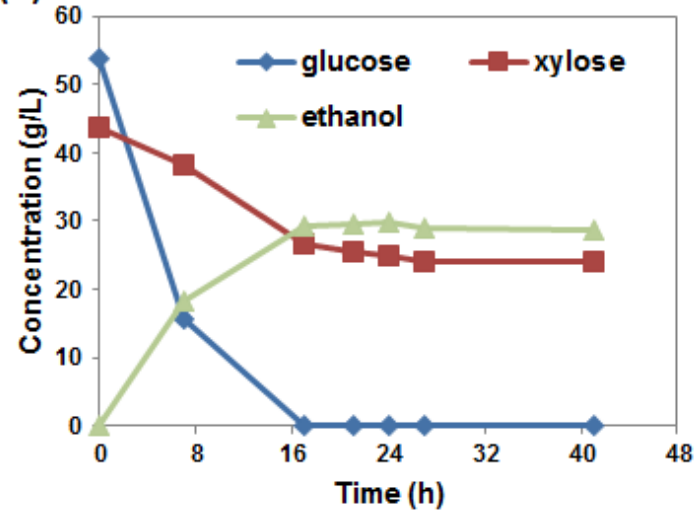

Fig. 4. Comparison of ethanol fermentation in YPX and YPDX medium by the strain YY5A and T5 at $40{ }^{\circ} \mathrm{C}$. (a) xylose fermentation by YY5A in YPX medium; (b) glucose/xylose co-fermentation by YY5A in YPDX medium; (c) xylose fermentation by T5 in YPX medium; and (d) glucose/xylose co-fermentation by T5 in YPDX medium

\section{SHCF and SSCF Processes for Lignocellulosic Ethanol Production at High- Temperature}

The SHCF process is commonly employed to maximize the performance of both enzymatic hydrolysis and fermentation processes for lignocellulosic ethanol production. The high concentration of sugar mixture can be used to produce ethanol by cofermentation. However, the high concentration of ethanol produced from glucose in the sugar mixture could be an inhibitory factor for further consuming xylose by recombinant co-fermenting $S$. cerevisiae at high temperature. Therefore, the SHCF process might not be suitable for lignocellulosic ethanol production at high temperature. However, the SSCF process is more favorable for efficient xylose fermentation at high temperature due to the lower initial concentrations of glucose and ethanol to inhibit xylose assimilation by recombinant $S$. cerevisiae. 
To assess the fermentation capacity of the thermotolerant mutant strain $\mathrm{T} 5$ in lignocellulosic hydrolysates by SHCF and SSCF processes, the fermentation in sugarcane bagasse hydrolysates at $40{ }^{\circ} \mathrm{C}$ was evaluated. The composition of the pretreated sugarcane bagasse is summarized in Table 1. During $24 \mathrm{~h}$ of SHCF, glucose was consumed completely within $17 \mathrm{~h}$. The xylose consumption was $15.3 \mathrm{~g} / \mathrm{L}$ (48\% of the initial xylose) and the ethanol production was $31.9 \mathrm{~g} / \mathrm{L}$ (Fig. 5a). The xylose consumption rate was slowed greatly after $17 \mathrm{~h}$ of co-fermentation, which was consistent with the results of cofermentation in defined medium at $40{ }^{\circ} \mathrm{C}$ (Figs. 2 and 4). The results correspond to the abovementioned hypothesis, which indicate that the high concentration of ethanol produced from glucose during co-fermentation is an important inhibitory factor for consuming xylose by co-fermenting $S$. cerevisiae at high temperature. During $24 \mathrm{~h}$ of $\mathrm{SSCF}$, the xylose consumption was $19.7 \mathrm{~g} / \mathrm{L}$ ( $78 \%$ of the initial xylose). After $120 \mathrm{~h}$ of $\mathrm{SSCF}$, the xylose consumption was $24.9 \mathrm{~g} / \mathrm{L}$ (99\% of the initial xylose), and the ethanol production was $36.0 \mathrm{~g} / \mathrm{L}$ (Fig. 5b). The results indicate that the xylose utilization in lignocellulosic hydrolysates by T5 was improved dramatically when using the SSCF process compared to the SHCF process at $40{ }^{\circ} \mathrm{C}$. In addition, the higher ethanol yield was obtained by the SSCF process. Enzymatic prehydrolysis process at high temperature (50 ${ }^{\circ} \mathrm{C}$ ) is often adopted prior to the SSF or SSCF process (hybrid process) for the liquefaction of pretreated lignocellulosic solid residues. The decreased viscosity in slurry allowed for easier pumping, stirring, and effectively increased the enzymatic hydrolysis efficiency (Öhgren et al. 2007; Cannella and Jørgensen 2014). However, releasing excessed glucose during the prehydrolysis might inhibit the xylose conversion for recombinant cofermenting $S$. cerevisiae strain in the following SSCF process at high temperature. Therefore, the SSCF process without the prehydrolysis is a preferred manner to reduce the co-stress of ethanol and temperature for xylose conversion in lignocellulosic ethanol production by xylose-fermenting $S$. cerevisiae at high temperature.

(a)

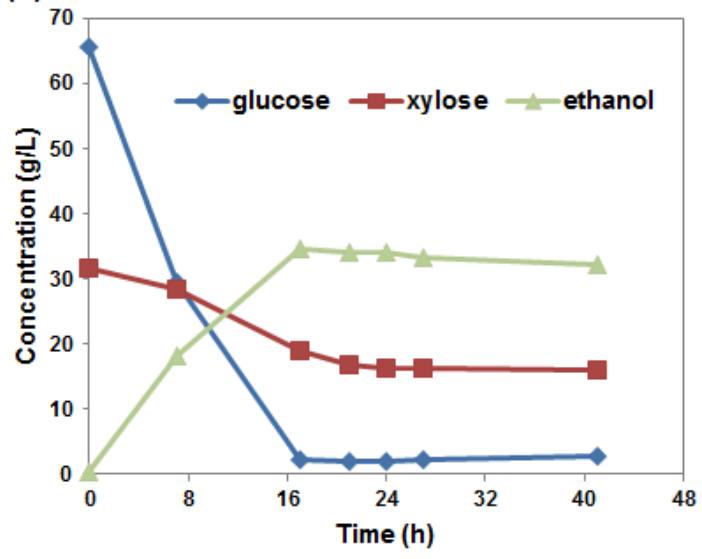

(b)

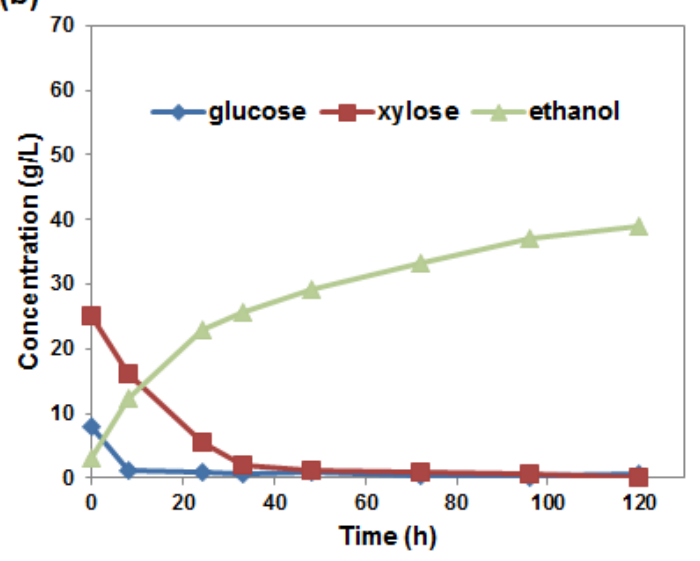

Fig. 5. (a) SHCF; and (b) SSCF of pretreated sugarcane bagasse hydrolysates by the mutant strain $\mathrm{T} 5$ at $40{ }^{\circ} \mathrm{C}$

\section{CONCLUSIONS}

1. The xylose fermentation by YY5A is impaired greatly at a high temperature of $40{ }^{\circ} \mathrm{C}$ whether in the defined medium of YPX or YPDX. 
2. The inhibition of ethanol on xylose utilization by recombinant xylose-fermenting Saccharomyces cerevisiae YY5A strictly corresponds to the conditions of temperature.

3. Although the xylose assimilation capacity of YY5A at high temperature could be improved markedly by EMS mutagenesis, the inhibition of ethanol on xylose utilization remains during the co-fermentation of glucose and xylose.

4. The simultaneous saccharification and co-fermentation (SSCF) process with a thermotolerant xylose-fermenting $S$. cerevisiae might be a crucial strategy for ethanol production from lignocellulose at high temperature.

\section{REFERENCES CITED}

An, M. Z., Tang, Y. Q., Mitsumasu, K., Liu, Z. S., Shigeru, M., and Kenji, K. (2011). "Enhanced thermotolerance for ethanol fermentation of Saccharomyces cerevisiae strain by overexpression of the gene coding for trehalose-6-phosphate synthase," Biotechnol. Lett. 33, 1367-1374. DOI: 10.1007/s10529-011-0576-X

Banat, I. M., Nigam, P., and Marchant, R. (1992). "Isolation of thermotolerant, fermentative yeasts growing at $52{ }^{\circ} \mathrm{C}$ and producing ethanol at $45^{\circ} \mathrm{C}$ and $50{ }^{\circ} \mathrm{C}$," World J. Microbiol. Biotechnol. 8, 259-263. DOI: 10.1007/BF01201874

Benjaphokee, S., Hasegawa, D., Yokota, D., Asvarak, T., Auesukaree, C., Sugiyama, M., Kaneko, Y., Boonchird, C., and Harashima, S. (2012). "Highly efficient bioethanol production by a Saccharomyces cerevisiae strain with multiple stress tolerance to high temperature, acid and ethanol," N. Biotechnol. 29(3), 379-386. DOI: 10.1016/j.nbt.2011.07.002

Birch, R. M., and Walker, G. M. (2000). "Influence of magnesium ions on heat shock and ethanol stress responses of Saccharomyces cerevisiae," Enzyme Microb. Technol. 26(9-10), 678-687. DOI: 10.1016/S0141-0229(00)00159-9

Cannella, D., and Jørgensen, H. (2014). "Do new cellulolytic enzyme preparations affect the industrial strategies for high solids lignocellulosic ethanol production?," Biotechnol. Bioeng. 111(1), 59-68. DOI: 10.1002/bit.25098

Chamnipa, N., Thanonkeo, S., Klanrit, P., and Thanonkeo, P. (2018). "The potential of the newly isolated thermotolerant yeast Pichia kudriavzevii RZ8-1 for hightemperature ethanol production," Braz. J. Microbiol. 49(2), 378-391. DOI: 10.1016/j.bjm.2017.09.002

Chen, W. H., Tsai, C. C., Lin, C. F., Tsai, P. Y., and Hwang, W. S. (2013). "Pilot-scale study on the acid-catalyzed steam explosion of rice straw using a continuous pretreatment system," Bioresource Technol. 128, 297-304. DOI: 10.1016/j.biortech.2012.10.111

Cunha, J. T., Romaní, A., Costa, C. E., Sá-Correia, I., and Domingues, L. (2019). "Molecular and physiological basis of Saccharomyces cerevisiae tolerance to adverse lignocellulose-based process conditions," Appl. Microbiol. Biotechnol. 103(1), 159175. DOI: $10.1007 / \mathrm{s} 00253-018-9478-3$

Ding, J., Huang, X., Zhang, L., Zhao, N., Yang, D., and Zhang, K. (2009). “Tolerance and stress response to ethanol in the yeast Saccharomyces cerevisiae," Appl. Microbiol. Biotechnol. 85(2), 253-263. DOI: 10.1007/s00253-009-2223-1

Dmytruk, O. V., Voronovsky, A. Y., Abbas, C. A., Dmytruk, K. V., Ishchuk, O. P., and Sibirny, A. A. (2008). "Overexpression of bacterial xylose isomerase and yeast host 
xylulokinase improves xylose alcoholic fermentation in the thermotolerant yeast Hansenula polymorpha," FEMS Yeast Res. 8(1), 165-173. DOI: 10.1111/j.15671364.2007.00289.x

Eklund, R., Galbe, M., and Zacchi, G. (1990). "Optimization of temperature and enzyme concentration in the enzymatic saccharification of steam-pretreated willow," Enzyme Microbial Technol. 12(3), 225-228. DOI: 10.1016/0141-0229(90)90043-P

Erdei, B., Frankó, B., Galbe, M., and Zacchi, G. (2012). "Separate hydrolysis and cofermentation for improved xylose utilization in integrated ethanol production from wheat meal and wheat straw," Biotechnol. Biofuels 5, Article number 12. DOI: 10.1186/1754-6834-5-12

Favaro, L., Jansen, T., and Van Zyl, W. H. (2019). "Exploring industrial and natural Saccharomyces cerevisiae strains for the bio-based economy from biomass: The case of bioethanol," Crit. Rev. Biotechnol. 39(6), 800-816. DOI: 10.1080/07388551.2019.1619157

Fonseca, G. G., Heinzle, E., Wittmann, C., and Gombert, A. K. (2008). "The yeast Kluyveromyces marxianus and its biotechnological potential," Appl. Microbiol. Biotechnol. 79(3), 339-354. DOI: 10.1007/s00253-008-1458-6

Ge, X. Y., Xu, Y., and Chen, X. (2013). "Improve carbon metabolic flux in Saccharomyces cerevisiae at high temperature by overexpressed TSL $\mathrm{T}_{1}$ gene," J. Ind. Microbiol. Biotechnol. 40, 345-352. DOI: 10.1007/s10295-013-1233-2

Hahn-Hägerdal, B., Karhumaa, K., Jeppsson, M., and Gorwa-Grauslund, M. F. (2007). Metabolic engineering for pentose utilization in Saccharomyces cerevisiae," Adv. Biochem. Eng. Biotechnol. 108, 147-177. DOI: 10.1007/10_2007_062

Ismail, K. S. K., Sakamoto, T., Hatanaka, H., Hasunuma, T., and Kondo, A. (2013). "Gene expression cross-profiling in genetically modified industrial Saccharomyces cerevisiae strains during high-temperature ethanol production from xylose," $J$. Biotechnol. 163(1), 50-60. DOI: 10.1016/j.jbiotec.2012.10.017

Jin, C., Zhang, X., Wang, X., Xiang, Y., Cui, X., Yin, Z., Sun, X., Ji, J., Wang, G., and Liu, H. (2019). "Effects of polyoxymethylene dimethyl ethers on the solubility of ethanol/diesel and hydrous ethanol/diesel fuel blends," Energy Sci. Eng. 7(6), 28552865. DOI: $10.1002 / \mathrm{ese} 3.466$

Jin, M., Gunawan, C., Balan, V., Lau, M. W., and Dale, B. E. (2012). "Simultaneous saccharification and co-fermentation (SSCF) of $\mathrm{AFEX}^{\mathrm{TM}}$ pretreated corn stover for ethanol production using commercial enzymes and Saccharomyces cerevisiae 424A(LNH-ST)," Bioresource Technol. 110, 587-594. DOI: 10.1016/j.biortech.2012.01.150

Jin, M., Sarks, C., Gunawan, C., Bice, B. D., Simonett, S. P., Narasimhan, R. A., Willis, L. B., Dale, B. E., Balan, V., and Sato, T. K. (2013). "Phenotypic selection of a wild Saccharomyces cerevisiae strain for simultaneous saccharification and cofermentation of AFEX ${ }^{\mathrm{TM}}$ pretreated corn stover," Biotechnol. Biofuels. 6, Article number 108. DOI: 10.1186/1754-6834-6-108

Kim, H. S., Kim, N. R., Yang, J., and Choi, W. (2011). "Identification of novel genes responsible for ethanol and/or thermotolerance by transposon mutagenesis in Saccharomyces cerevisiae," Appl. Microbiol. Biotechnol. 91(4), 1159-1172. DOI: 10.1007/s00253-011-3298-z

Kuyper, M., Hartog, M. M. P., Toirkens, M. J., Almering, M. J. H., Winkler, A. A., Van Dijken, J. P., and Pronk, J. T. (2005). "Metabolic engineering of a xylose-isomerase- 
expressing Saccharomyces cerevisiae strain for rapid anaerobic xylose fermentation," FEMS Yeast Res. 5(4-5), 399-409. DOI: 10.1016/j.femsyr.2004.09.010

Lu, Y., Cheng, Y. F., He, X. P., Guo, X. N., and Zhang, B. R. (2012). "Improvement of robustness and ethanol production of ethanologenic Saccharomyces cerevisiae under co-stress of heat and inhibitors," J. Ind. Microbiol. Biotechnol. 39(1), 73-80. DOI: 10.1007/s10295-011-1001-0

Lynd, L. R., Weimer, P. J., Van Zyl, W. H., and Pretorius, I. S. (2002) "Microbial cellulose utilization: Fundamentals and biotechnology," Microbiol. Mol. Biol. Rev. 66(3), 506-577. DOI: 10.1128/mmbr.66.3.506-577.2002

Ma, T. Y., Lin, T. H., Hsu, T. C., Huang, C. F., Guo, G. L., and Hwang, W. S. (2012). "An improved method of xylose utilization by recombinant Saccharomyces cerevisiae," J. Ind. Microbiol. Biotechnol. 39(10), 1477-1486. DOI: 10.1007/s10295012-1153-6

Meinander, N. Q., and Hahn-Hägerdal, B. (1997). "Influence of cosubstrate concentration on xylose conversion by recombinant, XYL1-expressing Saccharomyces cerevisiae: A comparison of different sugars and ethanol as cosubstrates," Appl. Environ. Microbiol. 63(5), 1959-1964. DOI: 10.1128/AEM.63.5.1959-1964.1997

Öhgren, K., Vehmaanperä, J., Siika-Aho, M., Galbe, M., Viikari, L., and Zacchi, G. (2007). "High temperature enzymatic prehydrolysis prior to simultaneous saccharification and fermentation of steam pretreated corn stover for ethanol production," Enzyme Microb. Technol. 40(4), 1100-1107. DOI: 10.1016/j.enzmictec.2006.05.014

Rajak, U., Nashine, P., and Verm, T. N. (2020). "Numerical study on emission characteristics of a diesel engine fueled with diesel-spirulina microalgae-ethanol blends at various operating conditions," Fuel. 262, Article ID 116519. DOI: 10.1016/j.fuel.2019.116519

Robak, K., and Balcerek, M. (2018). "Review of second generation bioethanol production from residual biomass," Food Technol. Biotechnol. 56(2), 174-187. DOI: 10.17113/ftb.56.02.18.5428

Sassner, P., Galbe, M., and Zacchi, G. (2006). "Bioethanol production based on simultaneous saccharification and fermentation of steam-pretreated Salix at high drymatter content," Enzyme Microbial Technol. 39(4), 756-762. DOI: 10.1016/j.enzmictec.2005.12.010

Shahsavarani, H., Sugiyama, M., Kaneko, Y., Chuenchit, B., and Harashima, S. (2012). "Superior thermotolerance of Saccharomyces cerevisiae for efficient bioethanol fermentation can be achieved by overexpression of RSP5 ubiquitin ligase," Biotechnol. Adv. 30(6), 1289-1300. DOI: 10.1016/j.biotechadv.2011.09.002

Sims, R. E. H., Mabee, W., Saddler, J. N., and Taylor, M. (2010). “An overview of second generation biofuel technologies," Bioresource Technol. 101(6), 1570-1580. DOI: 10.1016/j.biortech.2009.11.046

Sluiter, A., Hames, B., Ruiz, R., Scarlata, C., Sluiter, J., Templeton, D., and Crocker, D. (2008). Determination of Structural Carbohydrates and Lignin in Biomass (NREL/TP-510-42618), National Renewable Energy Laboratory, Golden, CO, USA.

Suutari, M., Liukkonen, K., and Laakso, S. (1990) "Temperature adaptation in yeasts: The role of fatty acids," J. Gen. Microbiol. 136(8), 1469-1474. DOI: 10.1099/00221287-136-8-1469

Wallace-Salinas, V., and Gorwa-Grauslund, M. F. (2013). "Adaptive evolution of an industrial strain of Saccharomyces cerevisiae for combined tolerance to inhibitors and 
temperature," Biotechnol. Biofuels. 6, article number 151. DOI: 10.1186/1754-68346-151

Watanabe, S., Saleh, A. A., Pack, S. P., Annaluru, N., Kodaki, T., and Makino, K. (2007). "Ethanol production from xylose by recombinant Saccharomyces cerevisiae expressing protein engineered $\mathrm{NADP}^{+}$-dependent xylitol dehydrogenase," $J$. Biotechnol. 130(3), 316-319. DOI: 10.1016/j.jbiotec.2007.04.019

Yanase, S., Hasunuma, T., Yamada, R., Tanaka, T., Ogino, C., Fukuda, H., and Kondo, A. (2010). "Direct ethanol production from cellulosic materials at high temperature using the thermotolerant yeast Kluyveromyces marxianus displaying cellulolytic enzymes," Appl. Microbiol. Biotechnol. 88(1), 381-388. DOI: 10.1007/s00253-0102784-Z

Zhang, J., Zhang, B., Wang, D., Gao, X., Sun, L., and Hong, J. (2015). "Rapid ethanol production at elevated temperatures by engineered thermotolerant Kluyveromyces marxianus via the NADP(H)-preferring xylose reductase-xylitol dehydrogenase pathway," Metab. Eng. 31, 140-152. DOI: 10.1016/j.ymben.2015.07.008

Article submitted: August 25, 2020; Peer review completed: October 25, 2020; Revised version received and accepted: December 24, 2020; Published: January 5, 2021.

DOI: $10.15376 /$ biores.16.1.1358-1372 